Pesq. Vet. Bras. 36(10):971-978, outubro 2016 DOI: 10.1590/S0100-736X2016001000009

\title{
Lesões podais em ovinos da Mesorregião Sudoeste do Rio Grande do Sul ${ }^{1}$
}

\author{
Caroline S. Silveira², Pedro A. Damboriarena ${ }^{3}$, Raissa M. Morais ${ }^{3}$, Maria Elisa \\ Trost $^{3}$, Ricardo Pozzobon ${ }^{4}$ e Bruno L. Anjos ${ }^{3^{*}}$
}

\begin{abstract}
Silveira C.S., Damboriarena P.A., Morais R.M., Trost M.E., Pozzobon R. \& Anjos B.L. 2016. [Foot lesions of sheep from southwestern Rio Grande do Sul.] Lesões podais em ovinos da Mesorregião Sudoeste do Rio Grande do Sul. Pesquisa Veterinária Brasileira 36(10):971-978. Laboratório de Patologia Veterinária, Universidade Federal do Pampa, Uruguaiana, RS 97500-970, Brazil. E-mail: anjosbl@gmail.com

Foot lesions in sheep are important causes of economic loss due to fall in productivity, reproduction, by spending on ineffective treatment and elimination of affected animals. The purpose of this study was described the main features of foot lesions of sheep from southwestern Rio Grande do Sul, as well as epidemiological aspects and the importance of occurrence of these lesions for sheep farming in the region. Epidemiological and clinic-pathological information of sheep herds from the region between April 2014 and April 2015 , by means of visits to farms. In the study were evaluated 27 sheep flocks on farms located in different municipalities. In 21 farms was reported occurrence of foot lesions in sheep having caused significant economic losses. About 1700 sheep, $10 \%$ of herds, showed different degree of lameness caused by foot lesions ranging from mild to severe. It was found that several factors, such as climate and breeding were favorable for the development of foot injuries which may be associated with different disorders and etiologic agents. Although these injuries are important, the control and prevention has proved ineffective. Also was observed that infectious pododermatitis (Footrot) may be the main foot disease of sheep in the region, and can be considered a neglected disease.
\end{abstract}

INDEX TERMS: Foot lesions, footrot, lameness, sheep, pathology.

RESUMO.- Lesões podais em ovinos são causas importantes de perdas econômicas por quedas na produtividade, na reprodução, por gastos com tratamentos ineficientes e com o descarte de animais afetados. Dessa forma, os objetivos foram descrever as principais características das lesões podais observadas em ovinos da Mesorregião Sudoeste do Rio Grande do Sul, seus aspectos epidemiológicos e a importância da ocorrência desses distúrbios para a criação de ovinos nessa região. Foram coletados dados epidemiológicos e clinicopa-

\footnotetext{
${ }^{1}$ Recebido em 17 de setembro de 2015.

Aceito para publicação em 19 de julho de 2016.

Parte da dissertação de mestrado do primeiro autor.

${ }^{2}$ Programa de Pós-Graduação em Ciência Animal, área de concentração em Sanidade Animal/Patologia Veterinária, Universidade Federal do Pampa (Unipampa), Uruguaiana, RS 97500-970, Brasil.

${ }^{3}$ Laboratório de Patologia Veterinária (LPV), HUVet, Unipampa, Uruguaiana, RS 97500-970, Brasil. *Autor para correspondência: anjosbl@gmail.com

${ }^{4}$ Clínica Médica de Grandes Animais, Universidade Federal do Pampa (Unipampa), Uruguaiana, RS 97500-970, Brasil.
}

tológicos de rebanhos ovinos da região entre abril de 2014 e abril de 2015 através de visitas técnicas em propriedades rurais. Foram avaliados rebanhos ovinos em 27 propriedades rurais localizadas em diferentes municípios, dos quais 21 registraram a ocorrência de lesões podais com relato de perdas econômicas significativas. Aproximadamente 1.700 ovinos, em média $10 \%$ dos rebanhos, apresentavam diferentes graus de claudicação decorrente de lesões podais que variavam de brandas a severas. Verificou-se que diversos fatores como clima e manejo foram favoráveis para o desenvolvimento das lesões podais e essas podem estar associadas a diferentes distúrbios e agentes etiológicos. No entanto, embora essas condições sejam importantes, o controle e a prevenção tem se mostrado ineficientes. Observou-se ainda que a pododermatite infecciosa dos ovinos (Footrot), parece ser a principal doença podal na região e atualmente pode ser considerada uma doença negligenciada.

TERMOS DE INDEXAÇÃO: Pododermatites, claudicação, ovinos, patologia. 


\section{INTRODUÇÃO}

Na maioria dos países onde a criação de ovinos se destaca pela importância econômica, a sanidade dos rebanhos é uma preocupação frequente dos produtores e tem sido o foco de inúmeras políticas governamentais (Winter 2008). As lesões podais são algumas das principais causas de perdas na ovinocultura por se tratarem de enfermidades frequentes e que causam redução da mobilidade dos animais, o que leva a desvalorização das carcaças, perdas nos índices reprodutivos e descarte dos ovinos afetados e seus produtos (Aguiar et al. 2011, Smith et al. 2014, Witcomb et al. 2014).

Em ovinos, as lesões podais de origem infecciosa são as mais frequentes e geralmente são secundárias à pododermatite infecciosa dos ovinos (Footrot), dermatite interdigital, abscesso de pé e laminite do banho, que são enfermidades que prevalecem em rebanhos ovinos de diferentes países e desencadeiam sérios problemas de dígitos com claudicação e até mesmo a morte dos animais por septicemia e caquexia (Ribeiro 2007, Winter 2008, Gargano et al. 2013). Menos comuns são enfermidades como a doença da linha branca, granuloma de pé, úlceras e crescimento excessivo de casco, essas de ocorrência esporádica e acometimento individual (Aguiar et al. 2011, Gargano et al. 2013). Atualmente, uma nova doença, a dermatite digital contagiosa dos ovinos (CODD), é relatada como a principal enfermidade podal dos ovinos no Reino Unido (Angell et al. 2014, Duncan et al. 2014, Angell et al. 2015). Entretanto, diferenciar essas enfermidades depende da identificação e caracterização das lesões podais, o que nem sempre é realizado de forma satisfatória. Muito disso se dá pela falta de consenso entre diversos trabalhos que descrevem essas enfermidades. Notam-se ainda que muitas informações buscam a diferenciação dessas enfermidades que, no entanto, parecem fazer parte de um único complexo, com características macroscópicas quase indistintas.

No Brasil, é relatada a ocorrência de algumas dessas doenças em várias regiões (Rodrigues et al. 2001, Cavalcanti et al. 2004, Ribeiro 2007, Aguiar et al. 2011, Gargano et al. 2013), no entanto, os métodos de controle têm sido pouco eficazes, muitas vezes pelo fato de serem baseados em características específicas de outras regiões ou países. No Rio Grande do Sul, essas enfermidades ainda são um grave problema para os criadores de ovinos e pouco tem sido feito para saná-las. Mesmo o Footrot, que é uma doença de notificação obrigatória no Brasil (Brasil 2013) praticamente não existem registros oficiais sobre sua situação nos rebanhos do país. Para que seja possível obter dados mais seguros sobre sua ocorrência e disseminação nos rebanhos se faz necessário diagnóstico correto e, para tal, a caracterização macroscópica de suas lesões é imprescindível.

Dessa forma, objetivou-se descrever as principais características das lesões podais observadas em ovinos da Mesorregião Sudoeste do Rio Grande do Sul, com ênfase também nos aspectos epidemiológicos envolvidos na ocorrência desses distúrbios, bem como na sua importância para a criação de ovinos dessa região.

\section{MATERIAL E MÉTODOS}

Foram realizadas avaliações clinicopatológicas em ovinos com lesões podais e distúrbios locomotores e criados de forma extensiva em propriedades rurais de municípios da Mesorregião Sudoeste Riograndense entre abril de 2014 e abril de 2015. As visitas ocorreram aleatoriamente após a solicitação dos serviços de diagnóstico no Laboratório de Patologia Veterinária da Unipampa, por parte de produtores rurais e médicos veterinários da região. Para tanto, foram aplicados questionários que abrangeram os principais aspectos epidemiológicos, clínicos e patológicos dos surtos e casos isolados de ovinos com lesões nos dígitos nas várias propriedades. As perguntas eram fechadas, tendo um número fixo de opções e de respostas, sendo elas do tipo dicotômicas e de múltipla escolha, e abrangeram questionamentos relacionados ao histórico da fazenda sobre distúrbios podais em ovinos, alimentação e manejo dos ovinos, lesões observadas, época de maior ocorrência, formas de tratamento, controle e prevenção de enfermidades podais e outras, destino dos ovinos doentes e mortos, bem como condições climáticas e ambientais (condições de solo e pluviosidade).

O nível de claudicação nos ovinos foi classificado em três níveis, com base na intensidade da claudicação e são eles: grau leve - quando o ovino apresentava leve claudicação; moderado - quando o membro tocava o solo, porém havia relutância em caminhar e hesitação em apoiar o casco; e acentuado - quando o membro mostrava-se flexionado (suspenso) sem apoiar no solo e extrema dificuldade em deambular.

Durante as visitas técnicas foi realizada a avaliação macroscópica dos ovinos com lesões podais nas propriedades e essas lesões classificadas em três graus de intensidade. A partir dos achados macroscópicos de cada ovino, foi estabelecido o(s) grau(s) dos distúrbios observados no animais em cada propriedade. Esses graus foram classificados em Grau I - dermatite discreta com hiperemia do rodete coronário; Grau II - dermatite moderada com podridão do casco e perda tecidual leve; e Grau III - com acentuada perda tecidual do casco e intensa reação cicatricial. Foram levados em consideração os diferentes graus, inclusive quando ocorriam em um mesmo animal.

\section{RESULTADOS}

Foram avaliados rebanhos ovinos em 27 propriedades rurais localizadas em diferentes municípios da região. Em todas as propriedades os ovinos eram criados de forma extensiva e na maioria dos casos com pastejo de forrageiras nativas. Das 27 propriedades visitadas, 21 registraram lesões podais em ovinos com relato de perdas econômicas significativas. 0 município com maior número de propriedades foi Uruguaiana (7) seguido por Santana do Livramento com seis, quatro em Itaqui, duas em Alegrete, uma em Maçambará e uma em Barra do Quaraí. Os rebanhos de ovinos das 21 propriedades, sem distinção de sexo, raça e idade totalizaram 16.990 animais, dos quais aproximadamente $1.700(10 \%)$ ovinos apresentavam algum grau de claudicação decorrente de lesões podais ou mesmo ataxia e morte. Os principais aspectos epidemiológicos desses casos podem ser visualizados no Quadro 1.

Foi relatado pela maioria dos criadores que no ano de 2014 houve uma maior ocorrência de lesões podais em ovinos, quando comparado a outros anos. Alguns criadores relataram ainda a ocorrência dessas alterações nos cascos e ovinos com claudicação durante todo o ano, com maior prevalência nos meses de março e abril (outono), outubro e novembro (primavera). 
Quadro 1. Principais aspectos epidemiológicos e macroscópicos de casos de lesões podais observadas em ovinos de propriedades rurais da Mesorregião Sudoeste Riograndense

\begin{tabular}{cccccc}
\hline $\begin{array}{c}\text { Propriedade } \\
\mathrm{N}^{\circ}\end{array}$ & Município & $\begin{array}{c}\text { No de ovinos } \\
\text { do rebanho }\end{array}$ & $\begin{array}{c}\text { No de ovinos } \\
\text { com claudicação }\end{array}$ & $\begin{array}{c}\text { Grau de lesão podal } \\
\text { por propriedade }\end{array}$ & $\begin{array}{c}\text { Tipo de } \\
\text { tratamento }\end{array}$ \\
\hline 1 & Uruguaiana & 108 & 10 & III & C + ATB \\
2 & S. Livramento* & 350 & 100 & III & C + PD \\
3 & Uruguaiana & 300 & 10 & II & C \\
4 & Uruguaiana & 2500 & 250 & I, II, III & PD + ATB \\
5 & Uruguaiana & 2000 & 400 & I, II, III & C + PD + ATB \\
6 & S. Livramento & 250 & 30 & III & C + PD + ATB \\
7 & Itaqui & 29 & 3 & III & P \\
8 & Itaqui & 120 & 12 & I, II & C \\
9 & Itaqui & 400 & 80 & I, II, III & C + PD + ATB \\
10 & Itaqui & 455 & 50 & I, II & C + ATB \\
11 & S. Livramento & 970 & 50 & I & C + PD + ATB \\
12 & S. Livramento & 4000 & 22 & III & C + PD + ATB \\
13 & S. Livramento & 1700 & 20 & II & C \\
14 & S. Livramento & 1200 & 120 & III & C \\
15 & Uruguaiana & 170 & 20 & II & C + PD + ATB \\
16 & Uruguaiana & 880 & 352 & I, II, III & C + PD + ATB \\
17 & Maçambará & 400 & 40 & III & ATB \\
18 & Alegrete & 78 & 3 & II & ATB \\
19 & Alegrete & 600 & 30 & I, II, III & PD + ATB \\
20 & Barra do Quaraí & 280 & 20 & II & C + PD \\
21 & Uruguaiana & 200 & 20 & I, II, III & C + ATB
\end{tabular}

* Santana do Livramento I = leve, $\mathrm{II}=$ moderado, $\mathrm{III}=$ acentuado; $\mathrm{C}$ = casqueamento, $\mathrm{PD}=$ pedilúvio, $\mathrm{ATB}=$ antibiótico.

Nas 21 propriedades com casos de enfermidades podais, os ovinos eram mantidos em piquetes com campo nativo e sob manejo extensivo, exceto na propriedade 1 , onde o sistema era de semiconfinamento e os animais eram mantidos no piquete constantemente, próximos às instalações. Na propriedade 5 , além de campo nativo, os ovinos também tinham acesso a campo com cultivo de azevém (Lolium multiflorum) e trevo-branco (Trifolium repens), irrigados por pivô central (Fig.1) e cerca de $20 \%$ apresentaram claudicação. As propriedades avaliadas apresentaram diferentes tipos de solo (especialmente argiloso, arenoso e pedregoso) e relevo, caracterizado por locais de várzea e planície. Foram observados ovinos com claudicação em propriedades com os diferentes tipos de solo e relevo no momento da visita e, segundo os produtores, as raças mais acometidas foram Corriedale, Ideal e Texel.

A maioria dos ovinos acometidos apresentava emagrecimento, alguns se mostravam apáticos e com sinais de dor em variados graus, desde animais com leve claudicação, ovinos com membro flexionado (Fig.2) até animais com acentuada dor com apoio das articulações cárpicas no solo, na tentativa de minimizar a pressão nos cascos durante o pastejo ("andar de joelhos") (Fig.3).

A avaliação macroscópica dos cascos revelou uma maior frequência dos graus II e III. Das 21 propriedades, 13 apresentaram ovinos com lesões podais nos graus II e III. Das 14 propriedades que apresentaram apenas um dos graus, oito delas apresentaram ovinos com apenas o grau III, cinco com o grau II e apenas uma com o grau I. Em 6/21 propriedades foram observados ovinos com os três graus de lesões podais (ver Quadro 1).

Todos os ovinos com claudicação apresentavam lesões podais próximas ao rodete coronário, especialmente na re- gião interdigital e/ou no casco. Macroscopicamente, foram observados dígitos com lesões caracterizadas por crescimento exacerbado e irregular do estojo córneo dos cascos (Fig.4); hiperemia e alopecia da comissura interdigital com integridade da pele (Fig.5); proliferação irregular de tecido de granulação interdigital e necrose (Fig.6); perda da integridade da pele interdigital com lesões profundas e necrose da região axial, que se estende desde a face palmar/plantar até a face dorsal, com acometimento da banda coronária (Fig.7); acentuada necrose interdigital com perda tecidual da falange distal e deformidades dos dígitos com posterior desprendimento dos cascos e odor pútrido (Fig.8); abscesso (Fig.9); descolamento dos cascos na região axial e abaxial sem lesão prévia da pele interdigital (Fig.10); úlcera da banda coronária da região lateral com possível progressão para descolamento da face abaxial do casco (Fig.11); cicatrização, alopecia, tumefação e defor-

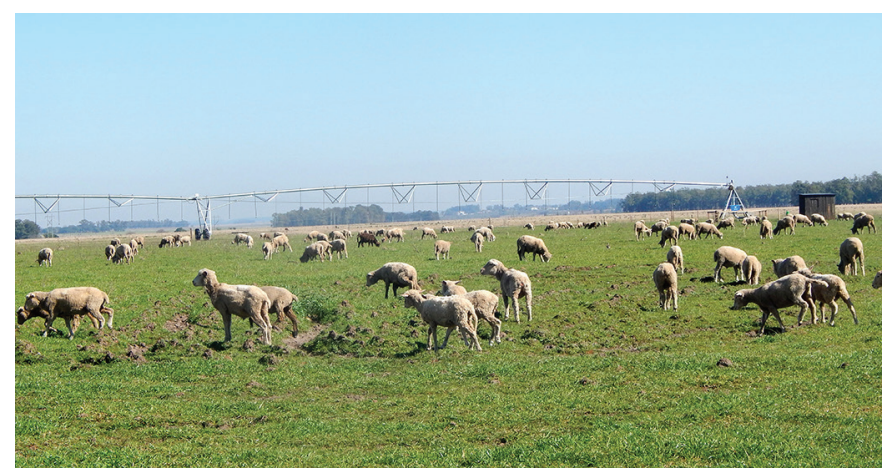

Fig.1. Alta lotação de ovinos em pastagens cultivadas em irrigação por pivô. 0 solo apresenta áreas irregulares que, com o funcionamento do pivô, tornam-se alagadiças. 


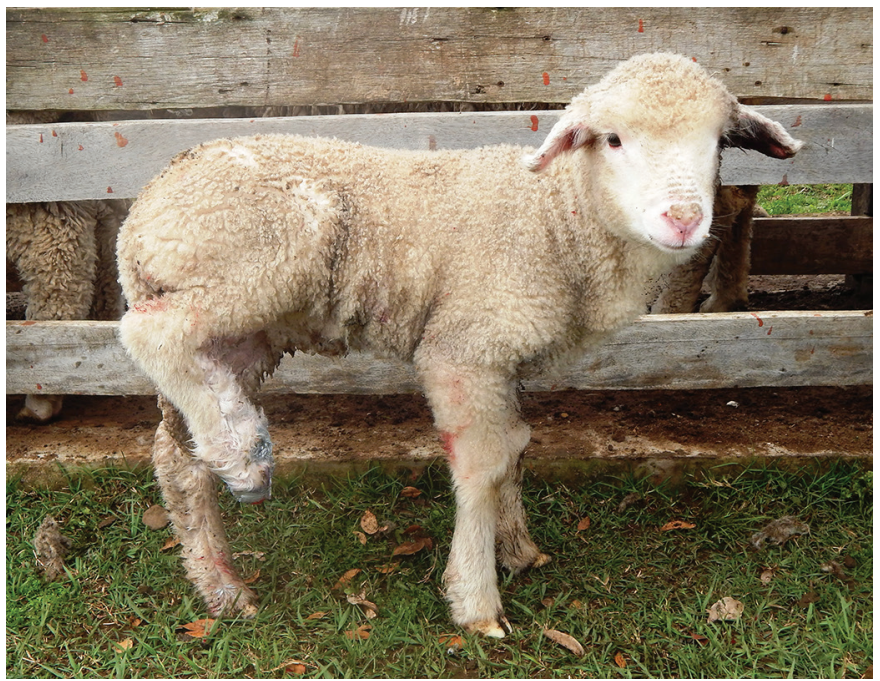

Fig.2. Ovino com membro pélvico direito flexionado e suspenso sem entrar em contato com o solo, decorrente de lesão podal acentuada.

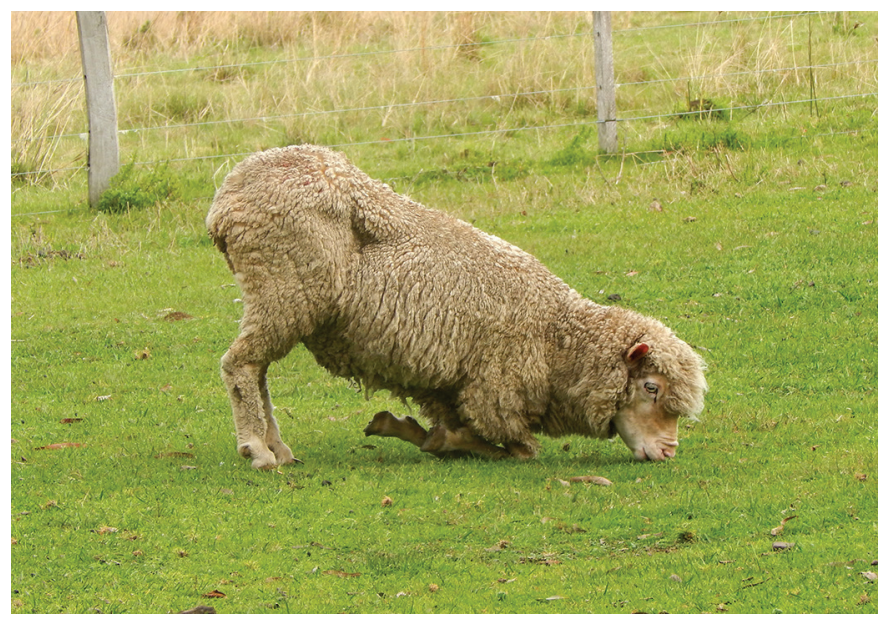

Fig.3. Ovino apoiado sobre as articulações cárpicas, na tentativa de se alimentar sem o contato dos cascos com o solo em detrimento a dor intensa.

mação da porção distal dos membros e/ou ausência dos dígitos (Fig.12) e hiperplasia da pele e subcutâneo interdigital (Fig.13).

Foram relatadas também diferentes abordagens terapêuticas para os ovinos doentes. Dos 21 estabelecimentos rurais com ovinos apresentando lesões podais, todos realizavam algum tipo de tratamento que consistia em isolamento, casqueamento, pedilúvio e antibioticoterapia. Em nenhuma propriedade os ovinos com lesões podais eram descartados do rebanho e nenhuma propriedade apresentava formas de manejo preventivo.

Segundo os criadores, a maiorias dos ovinos com lesões leves, quando tratados, se recuperavam, porém os ovinos que apresentavam deformidades nos dígitos e permaneciam na propriedade apresentavam atraso no desenvolvimento corporal, com perda de peso, que variava entre 5 e $20 \mathrm{~kg}$, quando comparado com animais sadios da mesma faixa etária. Esses ovinos, com frequência, apresentavam

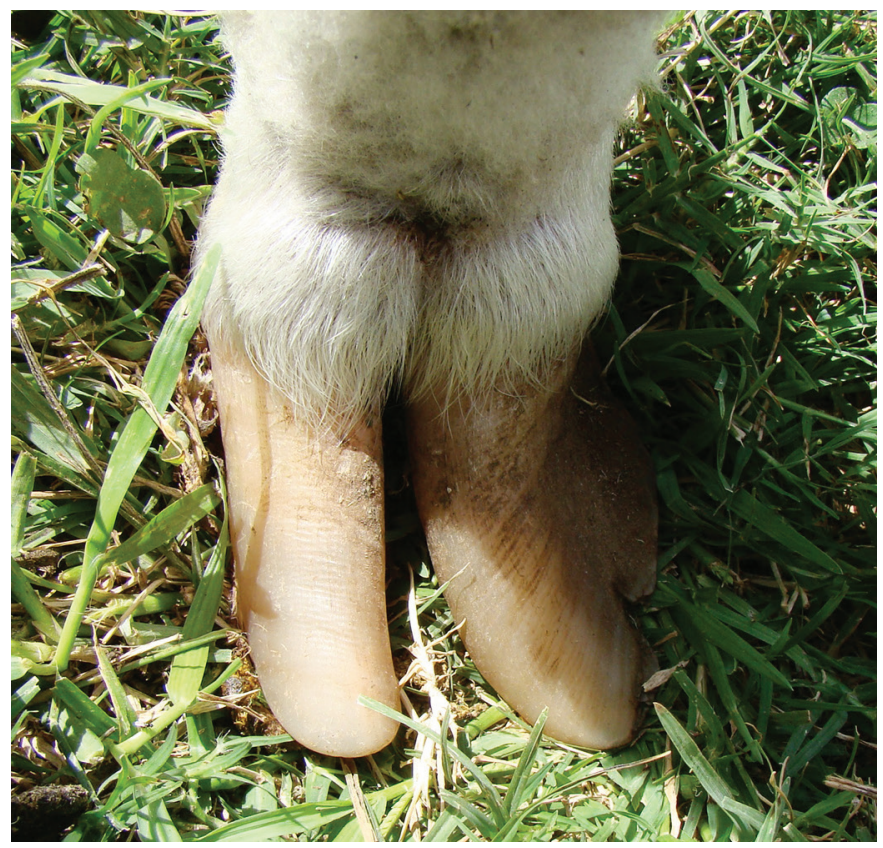

Fig.4. Casco com crescimento exacerbado e irregular da ceratina dura da pinça e da face abaxial do casco do membro pélvico de ovino.

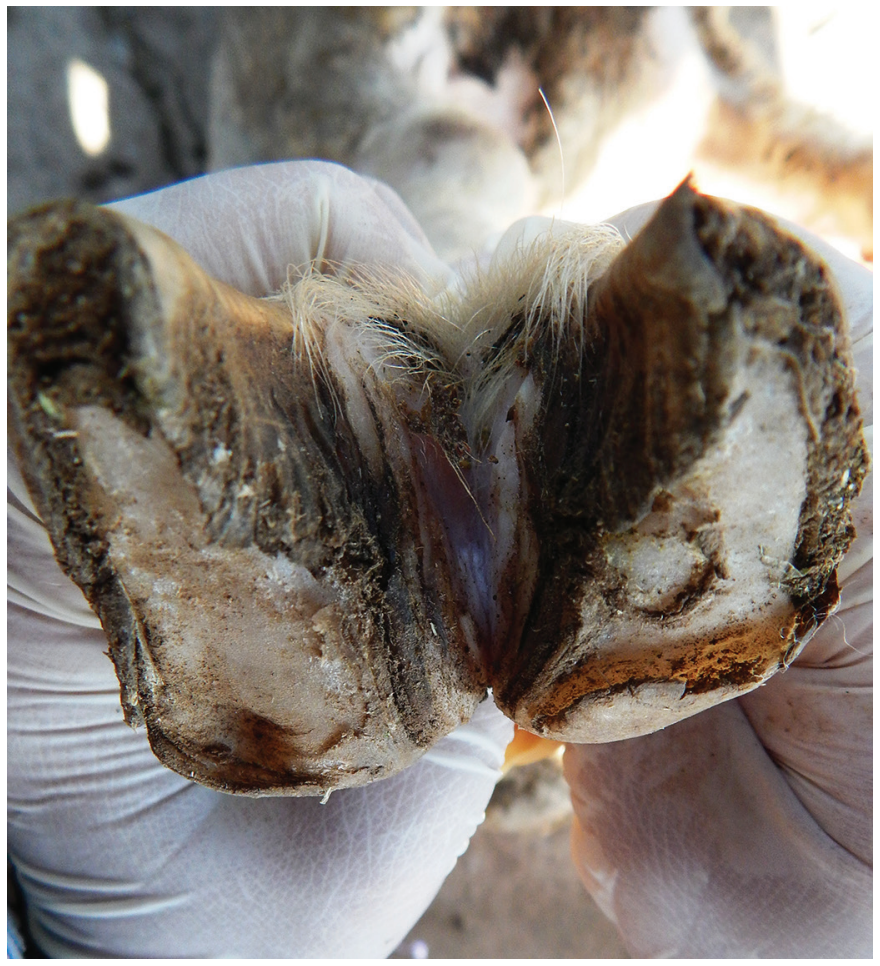

Fig.5. Região distal do membro torácico de ovino com dermatite interdigital e alopecia dessa região.

queda acentuada nos índices reprodutivos e esporadicamente apresentavam recidiva das lesões podais.

\section{DISCUSSÃO}

Lesões podais em ruminantes são distúrbios que causam sérias perdas para produtores rurais, pois resultam em 


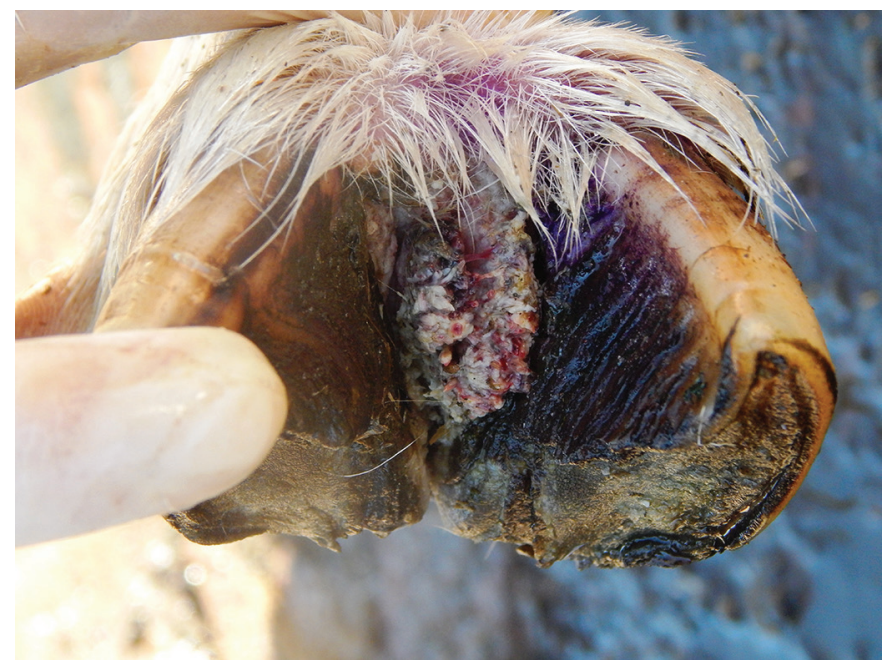

Fig.6. Proliferação irregular de tecido de granulação e dermatite no espaço interdigital de ovino.

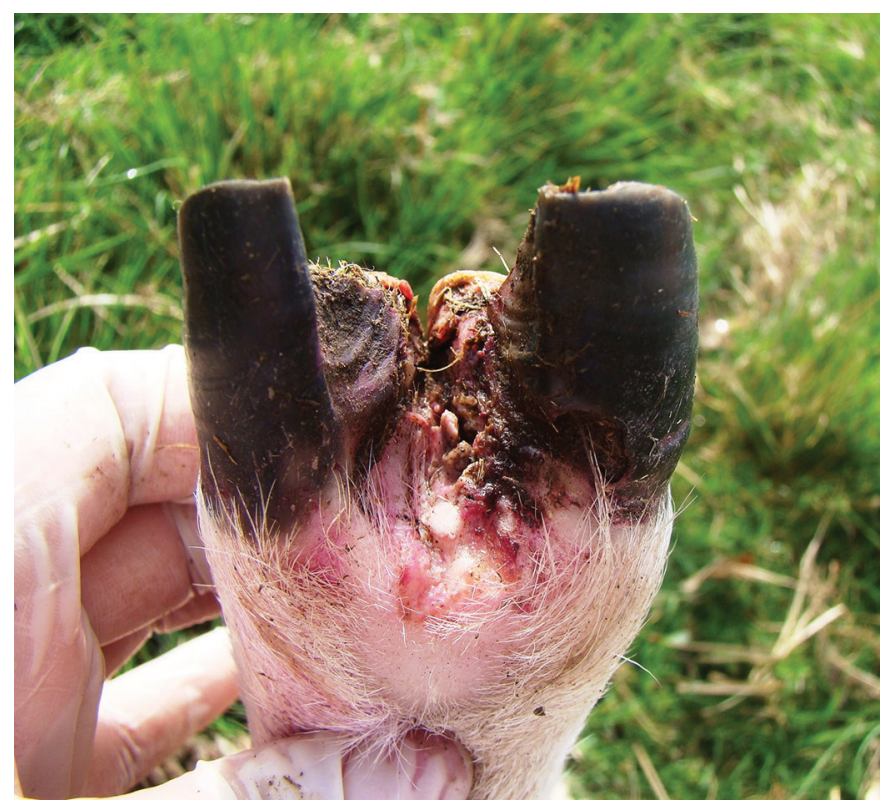

Fig.7. Membro pélvico de ovino com alopecia, hiperemia e necrose da pele interdigital com acometimento da banda coronária do casco.

prejuízos diretos tanto pela perda de peso dos animais como pelo déficit reprodutivo conforme observado em ovinos de algumas propriedades rurais aqui avaliadas. Essas perdas estão relacionadas à alta morbidade decorrente das lesões podais, acompanhada de perda de peso, diminuição no índice reprodutivo, desvalorização da lã, atraso de crescimento, miíases secundárias e ainda pelos gastos com produtos veterinários para o tratamento sintomático dos doentes (Rodrigues et al. 2001, Cavalcanti et al. 2004, Ribeiro 2007, Aguiar et al. 2011, Gargano et al. 2013, Smith et al. 2014, Witcomb et al. 2014).

As lesões podais observadas no presente estudo ocorreram com maior frequência nos meses da primavera e do outono, em anos com elevados índices pluviométricos e com solos úmidos o que propiciou um maior aparecimento de lesões nos cascos, tornando-se uma porta de entrada para as bactérias. Sabe-se que as condições ambientais de umidade durante o período chuvoso e lesões traumáticas nos cascos favorecem a desvitalização do espaço interdigital dos ovinos e acúmulo de matéria orgânica, tornando-o susceptível à infecção por agentes causadores de dermatites podais, bem como úlcera de

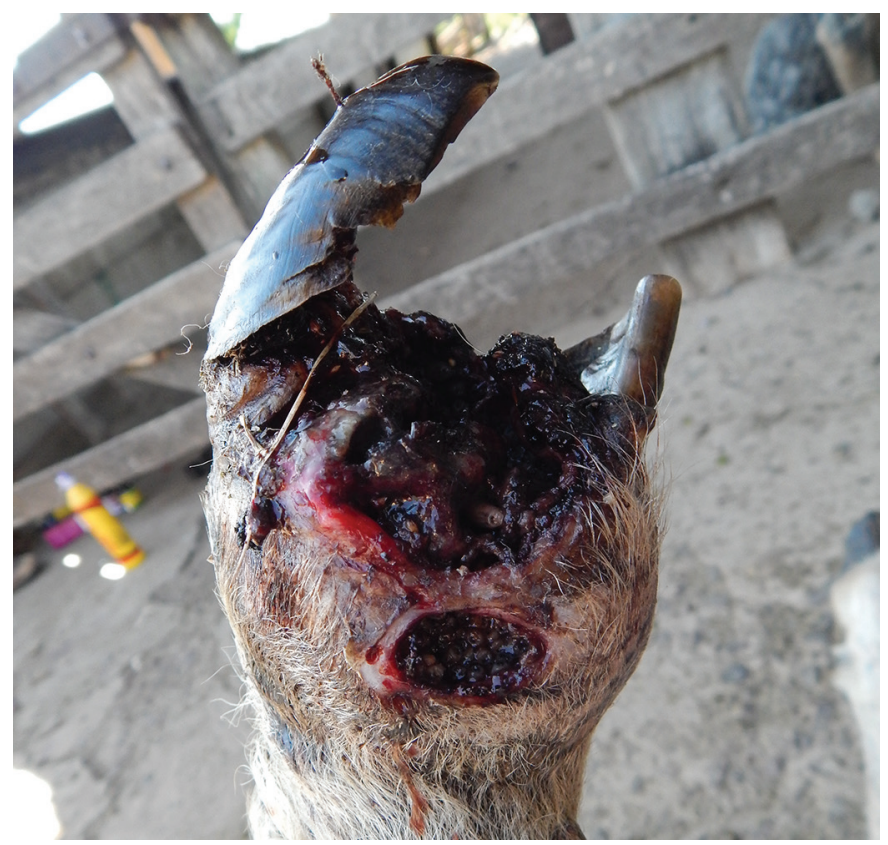

Fig.8. Região distal do membro torácico de ovino. Observa-se lesão severa com necrose que se estende até a região de falange proximal e miíase. Nota-se acentuada deformidade do membro e dos cascos.

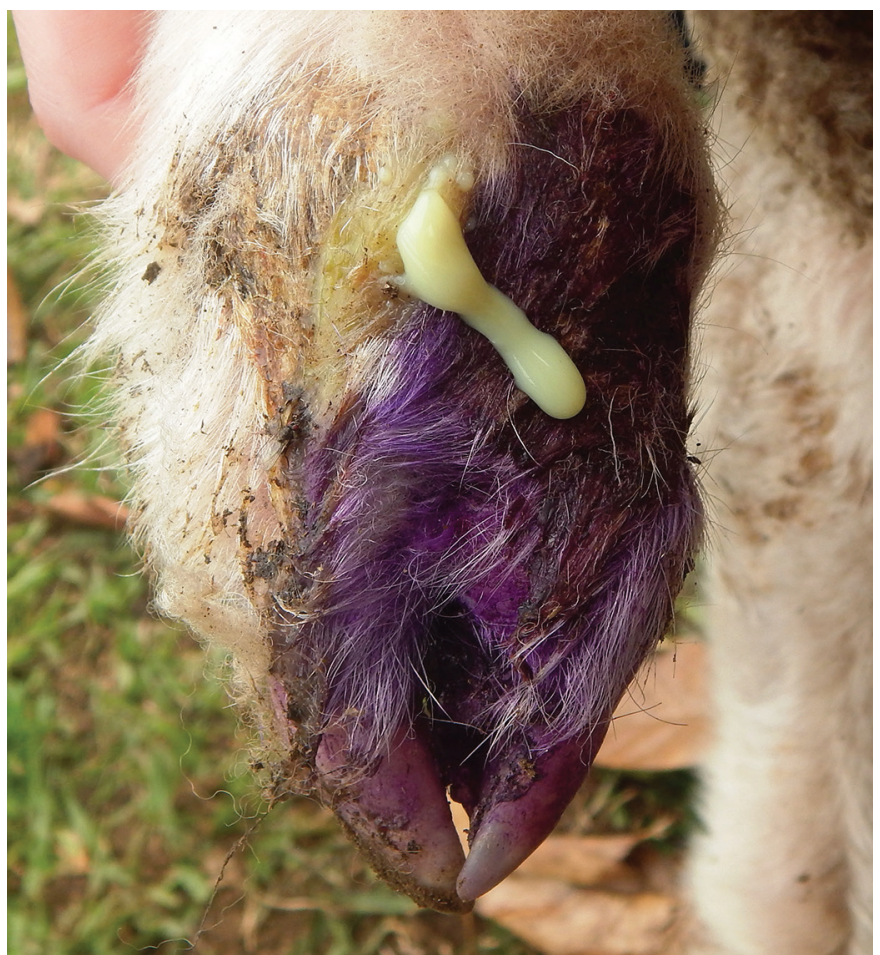

Fig.9. Face dorsal da falange média de ovino com lesão supurativa e necrótica interdigital. 
sola, granulomas e separação da muralha (Aguiar et al. 2011).

Os ovinos das propriedades avaliadas eram criados em sistema extensivo e em condições ambientais favoráveis ao desencadeamento das lesões podais (Winter 2008, Aguiar et al. 2011). Em uma das propriedades os ovinos paste-

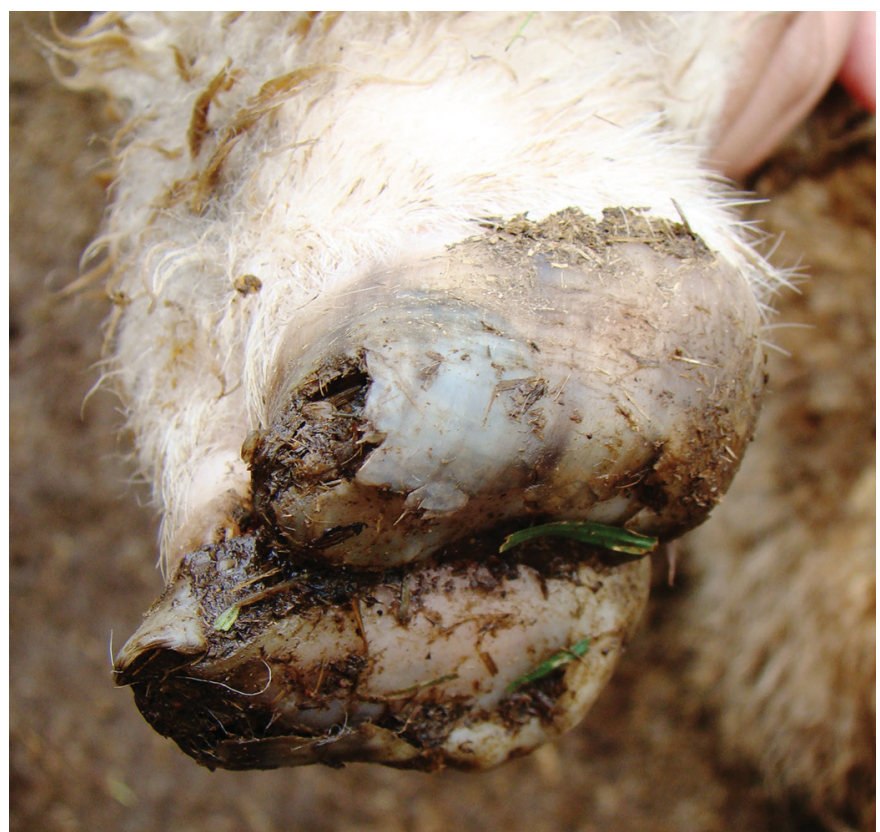

Fig.10. Dígitos de ovino com descolamento do casco tanto na região axial como abaxial sem lesão prévia da pele interdigital.

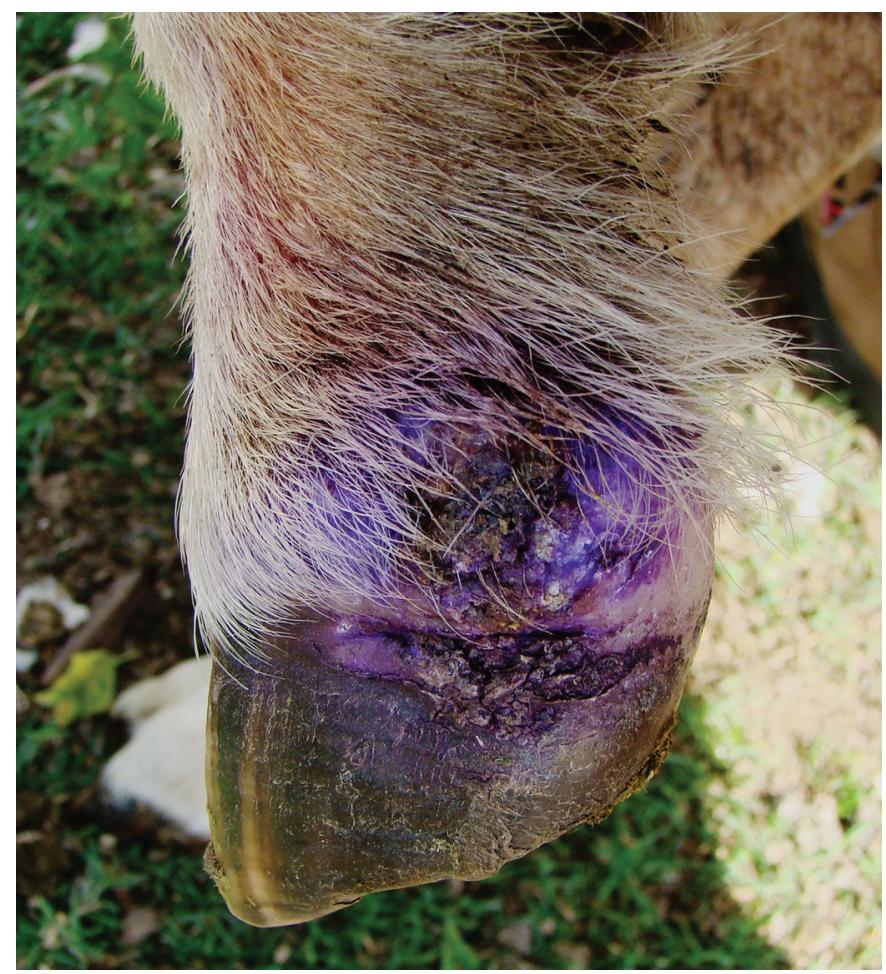

Fig.11. Região distal do membro torácico de ovino. Nota-se na face lateral do membro úlcera da banda coronária e descolamento leve da região abaxial do casco.

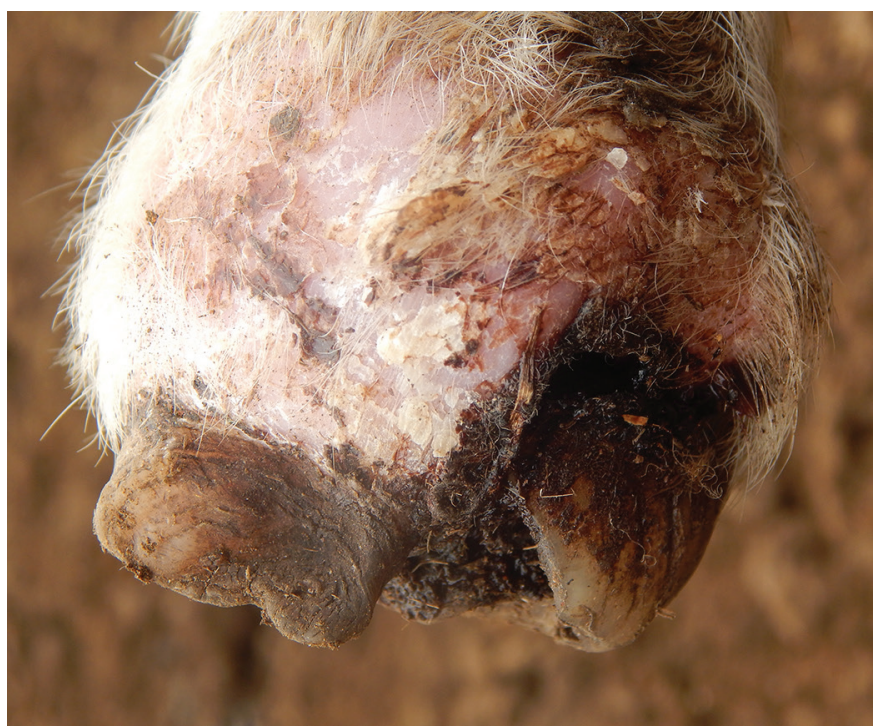

Fig.12. Região distal do membro pélvico de ovino com lesão crônica caracterizada por perda da arquitetura das lâminas do casco, dermatite crostosa e tumefação do membro.

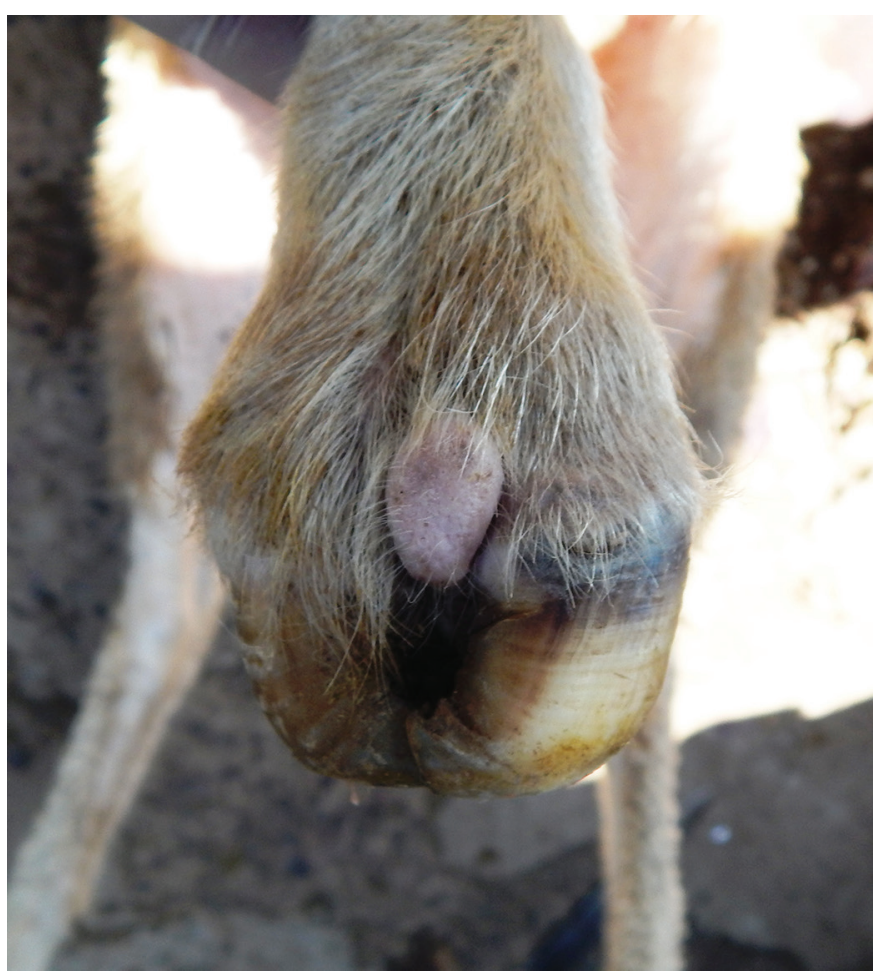

Fig.13. Região distal do membro torácico de ovino. Nota-se hiperplasia interdigital e deformidade do crescimento da pinça dos cascos.

javam em uma área irrigada por pivô, e cerca de $20 \%$ do rebanho apresentou claudicação. Esses dados são semelhantes aos obtidos por Aguiar et al. (2011) que também observaram surtos em propriedades nas quais os animais eram mantidos em piquete com sistema de irrigação e falha no escoamento de água o que propiciou o surgimento de lesão nos dígitos. 
O principal tratamento relatado pelos proprietários foi o casqueamento dos dígitos com crescimento exacerbado da muralha, com o intuito de evitar o acúmulo de matéria orgânica e favorecer a regressão das lesões. 0 casqueamento deve ser realizado com cautela, principalmente nos cascos sem lesões, com retirada apenas do excesso do tecido córneo, com diminuição do sangramento e exposição de tecidos sensíveis, uma vez que a ceratina dura da muralha protege essas estruturas e facilita a pisadura em superfícies mais duras e irregulares, bem como dificulta a transmissão de patógenos pelo contado próximo com material contaminado (Nicoletti 2004, Winter 2004, 2008, Smith et al. 2014). Provavelmente, um dos fatores que favoreceram a ocorrência dessas lesões nos rebanhos de ovinos da região tenha sido o casqueamento agressivo e demasiado nos cascos sem alterações prévias, e a falha no tratamento e manejo com ovinos que apresentaram diferentes tipos de lesões nos cascos. Muitos desses ovinos eram mantidos em campos com solo pedregoso o que pode levar a uma maior frequência de traumas.

Conforme observado nas propriedades investigadas, o grau de lesão mais frequente foi o grau III, seguido pelo grau II, o que auxilia demonstrar que há uma forte tendência por parte dos proprietários manterem esses animais com maior comprometimento dos cascos na propriedade sob tratamento, o que traz mais prejuízos e, em se tratando de lesões infecciosas, facilita a infecção de outros animais (Winter 2008, Smith et al. 2014). Percebe-se ainda que esse predomínio dos graus II e III pode estar diretamente ligado a constante progressão dos casos mais leves para casos mais graves das lesões.

Atualmente, são sugeridas inúmeras características, epidemiológicas, microbiológicas e morfológicas para caracterizar tipos distintos de doenças que acometem rebanhos de ruminantes e levam à claudicação (Nicoletti 2004, Bendigo 2007, Riet-Correa 2007, Winter 2008, Bennetti et al. 2009, Angell et al. 2014, Groneng et al. 2014, Angell et al. 2015). Alguns autores sugerem ainda que a avaliação macroscópica detalhada das lesões de pele interdigital e de cascos é um método eficaz para o diagnóstico e diferenciação das doenças de cascos em ovinos (Foddai et al. 2012). No entanto, percebe-se que as informações atuais sobre essas condições são confusas com relação à caracterização das lesões podais em ovinos o que dificulta a padronização das alterações em doenças clínicas distintas, e muitas vezes levam alguns pesquisadores a sugerirem que a maioria dessas condições faz parte de uma só entidade, compatível com Footrot, porém em diferentes estágios de acometimento dos dígitos, especialmente em detrimento as suas semelhanças macroscópicas e etiológicas (Bendigo 2007, Aguiar et al. 2011, König et al. 2011, Foddai et al. 2012, Raadsma \& Egerton 2013). As lesões observadas nos ovinos desse estudo são todas compatíveis com Footrot em vários estágios de evolução e intensidade das lesões e suas complicações.

Propõe-se atualmente que a dermatite interdigital desencadeada por Fusobacterium necrophorum causa claudicação (manqueira) aguda com lesões brandas, tornando o local hiperêmico e sem pelos (Winter 2008) e o não tratamento da lesão torna a área mais susceptível a contamina- ção por Dichelobacter nodosus, que desencadeia o Footrot com lesões profundas no espaço interdigital e banda coronária, além de necrose de lâminas do casco e odor fétido (Bendigo 2007). Na inspeção dos cascos e da pele interdigital dos ovinos em estudo notaram-se lesões em variados graus, desde leve, com desvitalização do espaço interdigital a lesões acentuadas com perda de estruturas do dígito, compatíveis com infecção por D. nodosus (Bendigo 2007, Ribeiro 2007, Winter 2008, Aguiar et al. 2011).

Conforme observado no estudo, a maioria das propriedades não apresentavam métodos preventivos para as dermatites podais. Atualmente, sabe-se que os principais meios de controle e prevenção para Footrot correspondem a práticas de casqueamento, pedilúvios, eliminação de casos crônicos, inspeção periódica dos animais introduzidos no rebanho, uso de piquetes livres de $D$. nodosus (14 dias sem trânsito animal), bem como antibioticoterapia, quando indicado, e através de programas e estratégias de vacinação (Rodrigues 2010, Dhungyel et al. 2014). Entretanto, é fundamental a divulgação de informações acerca da caracterização das lesões podais para que medidas profiláticas e de tratamento sejam as mais adequadas.

Vários padrões de lesão foram observados nos ovinos desse estudo, prevalecendo lesões características de Footrot em diferentes graus de severidade e suas complicações, como o abscesso de pé observado em um dos ovinos avaliados (Bendigo 2007, Ribeiro 2007, Winter 2008). Estudos anteriores demonstram que Footrot, (atribuído à infecção por $D$. nodosus em associação com F. necrophorum) é a principal enfermidade podal infecciosa que acomete rebanhos de pequenos ruminantes no Brasil (Rodrigues et al. 2001, Cavalcanti et al. 2004, Ribeiro 2007, Aguiar et al. 2011, Gargano et al. 2013). No entanto, enfermidades podais como dermatite interdigital causada por $F$. necrophorum (Winter 2008), dermatite digital contagiosa (COOD) causada por espécies de Treponema (Moore et al. 2005, Angell et al. 2015) são consideradas como diagnósticos diferenciais, embora, um trabalho recente aponte esses agentes como causadores de uma única doença podal (Footrot) (Frosth et al. 2015). Portanto, consideramos necessária uma padronização morfológica das lesões mais simplificada e o estabelecimento de um conceito mais preciso de Footrot.

\section{CONCLUSÕES}

O estudo demonstrou que lesões podais em ovinos são frequentes na Mesorregião Sudoeste do Rio Grande do Sul e estão associadas predominantemente a surtos de Footrot, e que esses distúrbios vêm sendo sistematicamente negligenciados, além da maioria das ações de combate, quando aplicadas, tem se mostrado ineficiente no controle e prevenção da enfermidade.

Muitas das ações de controle têm sido aplicadas de forma empírica, e poucas políticas de incentivo ao controle têm sido promovidas, o que fomenta a ideia equivocada de uma condição pouco impactante na criação de ovinos.

Agradecimentos.- À FAPERGS e ao CNPq pela concessão de bolsas de estudo a alunos de graduação e pós-graduação. 


\section{REFERÊNCIAS}

Aguiar G.M.N., Simões S.V.D., Silva T.R., Assis A.C.O., Medeiros J.M.A., Garino Junior F. \& Riet-Correa F. 2011. Foot rot and other foot diseases of goat and sheep in the semiarid region of northeastern Brazil. Pesq. Vet. Bras. 31(10):879-884.

Angell J.W., Duncan J.S., Carter S.D. \& Grove-White D.H. 2014. Farmer reported prevalence and factors associated withcontagious ovine digital dermatitis in Wales: a questionnaire of 511 sheep farmers. Prev. Vet. Med. 113:132-138.

Angell J.W., Blundell R., Grove-White D.H. \& Duncan J.S. 2015. Clinical and radiographic features of contagious ovine digital dermatitis and a novel lesion grading system. Vet. Rec. 176:1-9.

Brasil 2013. Instrução Normativa $\mathrm{n}^{\circ}$ 50, de 24 de setembro de 2013. Ministério da Agricultura, Pecuária e Abastecimento (MAPA), Brasília, DF. Disponível em <http://www.agricultura.gov.br/arq_editor/file/0arquivos/a/IN\%2050\%20Lista\%20DNO_\%20DOU\%20 2013_09_25.pdf> Acesso em 14 set. 2015.

Bendigo T.G. 2007. Footrot in sheep: diseases facts, diagnosis, treatment, prevention and damage control, benign footrot. Agriculture Notes. Departament of Primary Industries, State of Victoria, Austrália.

Bennett G., Hickford J., Sedcole R. \& Zhou H. 2009. Dichelobacter nodosus, Fusobacterium necrophorum and the epidemiology of footrot. Anaerobe 15:173-176.

Cavalcanti A.S.R., Aguiar G.M.N. \& Ayres M.C.C. 2004. Frequência da pododermatite em ovinos criados na microrrgegião dos Tabuleiros Costeiros no Estado da Bahia. XXXI Congr. Bras. Med. Vet., São Luis, Maranhão. (Abstract)

Dhungyel O., Hunter J. \& Whittington R. 2014. Footrot vaccines and vaccination. Vaccine 32:3139-3146.

Duncan J.S., Angell J.W., Carter S.D., Evans N.J., Sullivan L.E. \& Grove-White D.H. 2014. Contagious ovine digital dermatitis: An emerging disease. Vet. J. 201:265-268.

Foddai A., Green L.E., Mason S.A. \& Kaler J. 2012. Evaluating observer agrément of scoring systems for foot integrity and footrot lesions in sheep. BMC Veterinary Reserch. 8(65):1-8.

Frosth S., König U., Nyman A.K., Pringle M. \& Aspán A. 2015. Characterisation of Dichelobacter nodosus and detection of Fusobacterium necrophorum and Treponema spp. in sheep with different clinical manifestations of footrot. Vet. Microbiol. 179(1-2):82-90.

Gargano R.G., Benesi F.J., Birgel Junior E.H., Libera A.M.M.P.D., Gregory L., Sucupira M.C.A, Ortolani E.L., Gomes V. \& Pogliani F.C. 2013. Estudo retrospectivo das afecções locomotoras em ruminantes atendidos na Faculdade de Medicina Veterinária e Zootecnia da Universidade de São Paulo entre 2000 e 2012. Braz. J. Vet. Res. Anim. Sci. 50(4):286-293.

Groneng G.M., Green L.E., Kaler J., Vatn S. \& Hopp P. 2014. A longitudinal study of the risks for introduction of severe footrot into sheep flocks in the south west of Norway. Prev. Vet. Med. 113:241-248.

König U., Nyman A.K.J. \& Verdier K. 2011. Prevalence of footrot in Swedish slaughter lambs. Acta Vet. Scand. 53(27):2-5.

Moore L.J., Woodward M.J. \& Grogono-Thomas R. 2005. The occurrence of treponemes in contagious ovine digital dermatitis and the characterisation of associated Dichelobacter nodosus. Vet. Microbiol. 111(2/4):199-209.

Nicoletti J.L.M. 2004. Manual de Podologia Bovina. Manole, Barueri, SP. $126 \mathrm{p}$.

Raadsma H.W. \& Egerton J.R. 2013. A review of footrot in sheep: aetiology, risk factors and control methods. Livest. Sci. 156:106-114.

Ribeiro L.A.O. 2007. Foot rot dos ovinos, p.295-305. In: Riet-Correa F., Schild A.L., Lemos R.A.A. \& Borges J.R.J. (Eds), Doenças de Ruminantes e Equinos. Vol.1. $3^{\mathfrak{a}}$ ed. Varela, São Paulo.

Riet-Correa F. 2007. Abscesso de pé, p.199-201. In: Riet-Correa F., Schild A.L., Lemos R.A.A. \& Borges J.R.J. (Eds), Doenças de Ruminantes e Equinos. Vol.1. $3^{\mathrm{a}}$ ed. Varela, São Paulo.

Rodrigues C.A., Mendes L.C.N., Peiró J.R. \& Feitosa F.L.F. 2001. Ocorrência de um surto de "footrot" em um rebanho de ovinos na região de Araçatuba, SP, Brasil. Revta Educ. Contin. CRMV-SP 4(3):12-19.

Rodrigues P.R.C. 2010. Controle do Footrot em rebanho ovino no estado do Rio Grande do Sul: uso de vacina autógena e resposta sorológica. Dissertação de Mestrado. Disponível em <http://www.lume.ufrgs.br/ handle/10183/25022> Acesso em 14 set. 2015.

Smith E.M., Green O.D., Calvo-Bado L.A., Witcomb L.A., Grogono-Thomas R., Russell C.L., Brown J.C., Medley G.F., KilBride A.L., Wellington E.M. \& Green L.E. 2014. Dynamics and impact of footrot and climate on hoof horn length in 50 ewes from one farm over a period of 10 months. Vet. J. 201(3):295-301.

Winter A.C. 2004. Lameness in sheep. 2. Treatament and control. In Practice 26:130-139.

Winter A.C. 2008. Lameness in sheep. Small Rumin. Res. 76(1/2):58-63.

Witcomb L.A., Green L.E., Kaler J., Ul-Hassan A., Calvo-Bado L.A., Medley G.F., Grogono-Thomas R. \& Wellington E.M.H. 2014. A longitudinal study of the role of Dichelobacter nodosus and Fusobacterium necrophorum load in initiation and severity of footrot in sheep. Prev. Vet. Med. 115:4855 . 